GESTÃO DE OPERAÇÕES E LOGÍSTICA 


\title{
DESTINAÇÃO SUSTENTÁVEL DE PNEUS AGRICOLAS INSERVIVEIS: CONFIANÇA DOS AGRICULTORES E VIABILIDADE DE RECICLAGEM
}

\author{
SUSTAINABLE DESTINATION OF UNUSABLE AGRICULTURAL TIRES: \\ CONFIDENCE OF FARMERS AND VIABILITY FOR RECYCLING
}

Márcio Leandro Silva

Universidade Estadual do Oeste do Paraná

Geysler Rogis Flor Bertolini

Universidade Estadual do Oeste do Paraná

Jorge Lucio dos Santos Coelho

Universidade Estadual do Oeste do Paraná

Marco Antonio Sartori

Universidade Estadual do Oeste do Paraná

Data de submissão: 06 abr. 20 | 8. Data de aprovação:

02 dez. 2018. Sistema de avaliação: Double blind review.

Universidade FUMEC / FACE. Prof. Dr. Henrique Cordeiro

Jerry Adriani Johann

Martins. Prof. Dr. Cid Gonçalves Filho.

Universidade Estadual do Oeste do Paraná

\section{RESUMO}

O estudo objetivou identificar a percepção de consumo ambiental e consciência ambiental, moderada pela confiança atribuída pelo consumidor agrícola de uma empresa do ramo de recauchutagem de pneus agrícolas, contrapondo com a análise da viabilidade da implementação de uma usina de reciclagem de pneus inservíveis. A metodologia incluiu um estudo de caso no qual foi aplicado um instrumento de análise de natureza quantitativa, aplicando-se um questionário para I60 agricultores clientes da empresa, seguido da análise de viabilidade de uma usina de reciclagem de pneus. Resultados indicam que a consciência ambiental está correlacionada com a intenção de consumo, sob influência da variável moderadora confiança. Os agricultores não acreditam que suas ações podem produzir danos irreparáveis ao meio ambiente; não se preocupam com a relação entre os seres humanos e a natureza e não acreditam que as suas ações possam, de fato, provocar a destruição dos recursos naturais; apresentaram certa indiferença em relação às políticas adotadas pelas empresas ambientalmente corretas.Apesar disso, a análise de viabilidade indicou que a usina tem bons potenciais de geração de receitas e retorno sobre o investimento em até dois anos, pois há um mercado próprio para a sua destinação e geração de receitas, não dependendo dos consumidores agrícolas da organização. Desta forma, além de prover uma destinação adequada para os resíduos a usina traz retornos financeiros ao investidor dentro de um curto período de tempo, podendo, inclusive, servirem de recursos para as campanhas de conscientização ambiental dos agricultores.

\section{PALAVRAS-CHAVE}

Sustentabilidade. Pneus Inservíveis. Agricultores. Consciência ambiental. Usina recicladora. 


\section{ABSTRACT}

The study aimed to identify the perception of environmental consumption and environmental awareness, moderated by the trust attributed by the agricultural consumer of a company in the field of retreading of agricultural tires, opposing with the feasibility analysis of the implementation of a waste tire recycling plant. The methodology included a case study in which an analytical instrument of quantitative nature, was applied, applying a questionnaire to I 60 farmers the company's customers, followed by the feasibility analysis of a recycling plant of tires. Results indicate that environmental awareness is correlated with the intention of consumption, under the influence of the moderating confidence variable. Farmers do not believe that their actions can produce irreparable damage to the environment; they do not care about the relationship between humans and nature and do not believe that their actions can actually cause the destruction of natural resources; presented some indifference towards the policies adopted by environmentally correct companies. Nevertheless, the feasibility analysis indicated that the plant has good potential to generate revenues and return on investment in up to two years, because there is a proper market for its destination and revenue generation, not depending on the organization's agricultural consumers. In this way, in addition to providing a suitable destination for the waste, the plant brings financial returns to the investor within a short period of time, and may even serve as resources for farmers' environmental awareness campaigns.

\section{KEYWORDS}

Sustainability. Insectible Tires. Farmers. Environmental awareness. Recycling plant.

\section{INTRODUÇÃO}

Em razão da grande preocupação com a saúde pública e o meio ambiente, o Brasil tem criado políticas públicas visando a destinação adequada dos pneumáticos para coibir a importação de pneus usados, uma vez que impactos ambientais ocasionados pela disposição final inadequada de pneus inservíveis são significativamente negativos (ALVES, et al., 20I5).

Segundo Marinho et al. (20I2), o processo de avaliação de impactos ambientais deve buscar alternativas tecnológicas mais limpas e eficientes que ofereçam menor dano ao ambiente.
Para tanto, foi criado o Programa Nacional de Coleta e Destinação de Pneus Inservíveis no Brasil, a fim de cumprir com a norma estabelecida pelo CONAMA (Conselho Nacional do Meio Ambiente), conforme Resolução CONAMA número 259 , de 26 de agosto de 1999.A partir de então, as empresas foram impelidas a se adaptarem às novas regras criadas, sob pena de sofrerem sansões pelo descumprimento (FLORIANI; FURLANETTO; SEHNEM, 2016).

Paralelamente, a intensificação de políticas ambientais visando o desenvolvimento econômico sustentável corroborou para o aumento das pesquisas que objetivam a 
busca de alternativas ambientalmente adequadas para a destinação de resíduos. Ao longo dos anos um número crescente de empresas vem reconhecendo os benefícios de políticas e práticas sociais, o que se confirma por meio de uma série de estudos empíricos que apontam a existência de impactos positivos, inclusive relacionados ao desempenho econômico dessas organizações (KRAEMER, 2005).

$A$ recuperação e destinação correta de resíduos contribui para aumentar a sustentabilidade do Planeta ao diminuir a necessidade de extração de recursos naturais para atender as necessidades de produção de bens e serviços demandados pela sociedade (JESUS; BARBIERI, 20 I3).

Verifica-se que os estudos relacionados à sustentabilidade em processos de destinação sustentável de pneus, abordam unidades de análise variadas, que englobam os ganhos ao meio ambiente (ONUAGULUCHI; PANESAR, 20I4; MEDDAH, et al., 20।4; CINTRA, et al., 20I4; BAUER, et al., 20I5;TORRETTA, et al., 20 I 5; ZANETTI, et al., 20I5; SADEK ; EL-ATTAR, 2015 ; ALVES, et al., 20I5; SU, et al., 20I5; RAMIREZ, et al., 20I5; THOMAS; CHANDRA GUPTA, 20l6; FLORIANI, et al., 20I6; THOMAS; GUPTA ; PANICKER, 2016; KASHANI, et al., 2017; GUO ,et al., 20I7); o reaproveitamento dos resíduos de pneus (LAGARINHOS; TENÓRIO, 20I2; URUBURU, et al., 20 I 3; SELLITTO, et al., 20 I 3; MELLONE, SANTOS, SHIBAO, 20I3; FREITAS; NÓBREGA, 20I4; ONUAGULUCHI; PANESAR, 20I4; CINTRA, et al., 20I4; CINTRA, et al., 20 I4; MEDDAH, et al., 20 I4; SU, et al., 20 I5; RAMIREZ, et al., 20 I 5; TORRETTA, et al., 20 I 5; ZANETTI, et al., 20 I 5; SADEK; EL -ATTAR, 20 I 5; BAUER, et al., 20 I 5;ALVES, et al., 20I 5; FLORIANI, et al., 20 I6;THOMAS, et al., 2016;THOMAS ; CHANDRA GUPTA, 2016; KASHANI, et al., 20I7; GUO et al., 20 I7); e o processo de logística reversa (GARDIN, et al., 2010 ; LAGARINHOS; TENÓRIO, 201 2; ALVES, et al., 20I5; BAUER, et al., 20 I5).

Verifica-se assim uma lacuna de estudo quanto à percepção de consumo ambiental e consciência ambiental, moderada pela confiança atribuída pelo consumidor às organizações na execução das respectivas práticas, contrapondo com a análise da viabilidade da implementação do processo de reciclagem de pneus inservíveis.

Além disso, percebeu-se com o presente estudo que são escassas as pesquisas que foquem na destinação adequada especificamente de pneus agrícolas inservíveis, considerando-se sua logística de transportes e técnicas de reaproveitamento, tendo em vista sua composição diferenciada, bem como suas dimensões e peso elevados. A despeito disso, há nas pesquisas técnicas de destinação sustentável de pneus inservíveis alternativas viáveis também para pneus agrícolas.

Desta forma, o objetivo deste artigo é identificar a percepção de consumo ambiental e consciência ambiental, moderada pela confiança atribuída pelo consumidor agrícola de uma empresa do ramo de recauchutagem de pneus agrícolas, contrapondo com a análise da viabilidade da implementação de uma usina de reciclagem de pneus inservíveis.

Conforme afirmam Abreu, Armond-deMelo e Leopoldino (20II), há uma clara tendência de que a legislação ambiental brasileira caminhe no sentido de tornar as empresas cada vez mais responsáveis por todo o ciclo de vida de seus produtos, intensificando, portanto, a necessidade de se 
encontrar as melhores alternativas para a destinação dos resíduos pneumáticos. Ainda de acordo com os autores, as empresas podem se beneficiar dessas ações como forma de incremento do seu diferencial competitivo, além de abrirem espaço para o desenvolvimento de novos produtos (ABREU, et al., 20I I).

Corroboram Brandalise e Bertolini (20I4), enfatizando que resistir a inovações que reduzem o impacto ambiental resultará em perda de competitividade às organizações. Desta forma, torna-se fundamental o investimento em políticas e ações que busquem trazer benefícios ao meio ambiente e à sociedade de maneira geral.

Sustenta-se o esforço da presente pesquisa pelo fato da produção em larga escala desse produto que, se destinado incorretamente quando inservível, gera sérios danos ao meio ambiente, prejudicando consideravelmente os ecossistemas.

\section{Quadro Teórico}

O referencial teórico utilizado como embasamento para esta pesquisa foi alicerçado na percepção ambiental do consumidor, nos conceitos relacionados aos pneus inservíveis, nas formas de reaproveitamento e reciclagem desses pneus, bem como a discussão da coletânea de estudos produzidos sobre o tema.

\section{Consciência e consumo ambiental moderado pela confiança}

Para Schlegelmilch, Bohlen e Diamantopoulos (1996), a consciência ambiental pode ser definida como um composto multidimensional formado por elementos atitudinais, comportamentais e cognitivos. Conforme os autores, a mensuração do nível real de consciência ambiental de uma pessoa seria possível a partir da análise da sua preocupação ou interesse pelo tema, seus comportamentos passados, atuais e futuros e o quanto o impacto de suas ações no ambiente é compreendido.

O consumo sustentável pode ser definido como o consumo de bens e serviços, respeitando os recursos ambientais, de forma a garantir o atendimento das necessidades presentes sem comprometer 0 atendimento das necessidades das gerações futuras (HEAP; KENT, 2000). Alinhado a isso, Cooper (2002) afirma que o consumo sustentável tem como característica um padrão de consumo que atenda às necessidades básicas juntamente com a minimização da degradação ambiental.

Embora exista relação entre consciência ambiental e consumo, muitos estudos têm identificado um gap entre o discurso dos consumidores e a prática. Algumas vezes, mesmo aquelas pessoas identificadas como tendo um alto nível de consciência ambiental não demonstram um comportamento de consumo diferenciado e, por vezes, nem mesmo uma intenção de consumir essa categoria de produto.

Segundo pesquisa realizada por Bray, Johns e Kilburn (20II), uma das possíveis explicações para esse gap é a falta de confiança em relação à ética dos varejistas. Neste aspecto a confiança que o consumidor deposita nas organizações empresariais pode ser considerada como um fator que pode influenciar moderando a relação entre a consciência ambiental e o consumo ambiental. Inferindo-se a partir deste estudo que, quanto maior a confiança na organização, maior o consumo ambiental.

Para Morgan e Hunt (1994) a confiança e o comprometimento são centrais para o desenvolvimento de relacionamentos 
duradouros, sendo a confiança o principal fator determinante do compromisso. Para Moorman, Deshpande e Zaltman (1993), a confiança é baseada no caráter, relacionada às características comportamentais (integridade, intenções, previsibilidade, abertura, discrição) e baseada na competência do parceiro (expertise operacional, habilidade interpessoal e de negociação, discernimento). Morgan e Hunt (I 994), Ganesan (1994) e Doney e Cannon (1997) acrescentam que, além dos aspectos acima abordados, a confiança é baseada também em benevolência, a crença na qual "o comprador acredita que o vendedor tenha intenções e motivos que são benéficos para o comprador, quando de novas e inusitadas situações” (GANESAN, 1994, p. 3).

$\mathrm{Na}$ pesquisa conduzida por Grohmann et al. (20I2), o tema escolhido foi o de relacionar comportamento do consumidor com consciência ambiental e, num primeiro momento, constatou-se a relevância do assunto, pois foram encontrados muitos estudos que tratavam dessa temática.

No presente estudo as respectivas variáveis foram medidas seguindo o modelo proposto por Elias et al. (2013), com objetivo entender como as variáveis, consciência ambiental, consumo ambiental e confiança estão presentes nos agricultores, clientes do serviço de recalchutagem de pneus agrícolas realizado pela organização em estudo, uma vez que esta elenca dentre os seus valores, a preocupação com a sustentabilidade e meio ambiente.

\section{Pneus inservíveis}

De acordo com a Associção Nacional da Inústria de Pneumáticos - ANIP (20I7), os pneus inservíveis são aqueles que não podem mais rodar em veículos automotivos de qualquer natureza, ou seja, todas as formas de recondicionamento foram esgotadas e, a partir de então, as alternativas para destinação correta desses resíduos são as derivadas da reciclagem.

Uma vez que se tornem inservíveis, os pneus podem ser reaproveitados na valoração energética, fabricação de novos produtos, além de possuírem aplicações na pavimentação asfáltica, construção civil, construção de aterros sanitários, dentre outras.

Segundo Rodrigues e Henkes (2015), a ideia de reutilização de pneus é muito antiga, mas sua ação se deu somente após a Segunda Guerra Mundial, devido à dificuldade na obtenção de matéria-prima para a produção de pneus novos. Os pneus, quando trocados por novos, são descartados após o término de sua vida útil. Este descarte pode ocorrer em empresas que realizam a troca dos usados pelos novos ou muitas vezes o consumidor descarta estes pneus em locais inapropriados, como em rios, aterros e até mesmo em locais de coleta de lixo comum (FLORIANI; FURLANETTO; SEHNEM, 20I6).

\section{Logística reversa}

No contexto da reciclagem ou reaproveitamento de pneus, um dos principais fatores que dificultam a destinação correta dos respectivos resíduos é a logística reversa.

De acordo com Gardin, Figueiró, e Nascimento (20l0), apoiados no estudo de Rogers e Tibben-Lembke ( 1998), a logística reversa é um processo de planejamento, implementação e controle da eficiência e custo efetivo do fluxo de matérias-primas, estoques em processo, produtos acabados e as informações do ponto de consumo para o ponto de origem. Para Lagarinhos e Tenório (2012) a logística reversa está as- 
sociada ao retorno de produtos pós-venda com o intuito de reciclar, reaproveitar ou simplesmente definir uma destinação correta dos resíduos. No caso dos pneus agrícolas inservíveis, os problemas ligados à logística reversa se agravam, considerando as dimensões e peso dos respectivos pneus.

\section{Principais destinações dos pneus inservíveis}

De acordo com dados da Confederação Nacional da Inústria (CNI), as principais destinações dos pneus insersíveis são o coprocessamento em fornos de clínquer, laminação para fabricação de artefatos de borracha, reciclagem, e a industrialização do xisto (CONFEDERAÇÃO NACIONAL DA INDÚSTRIA, 20I4).

Entre 1999 e 2012, a CNI investiou um total de $\mathrm{R} \$ 194$ milhões no processo de destinação dos resíduos pneumáticos. Apenas em 201 I, o custo do sistema foi de $R \$ 63,6$ milhões, distribuídos por tipo de destinação (Tabela I).
Ainda de acordo com os dados da CNI (Confederação Nacional da Indústria, 2014), 67\% dos pneus inservíveis coletados são destinados na valorização enérgica nas cimenteiras, porém há outras formas de destinação desses resíduos no Brasil (Tabela 2).

Após o início do controle sobre os resíduos pneumáticos, parcerias entre a indústria cimenteira e entidades como a ANIP, permitiram que grande parte do volume dos pneus inservíveis pudessem ser reaproveitados em fornos de clínquer, por coprocessamento, representanto, em 2015, $59,16 \%$ do total destinado de forma sustentável (IBAMA, 20I5).

\section{Viabilidade Econômica e Financeira}

Campos (2007) afirma que a Taxa Interna de Retorno de um investimento deve ser entendida como a taxa de juros de um investimento no qual o valor presente do fluxo de caixa é igual a zero. Essa taxa tem característica como uma renumeração do capital investido, sendo

TABELA 1 - Investimentos por tipo de destinação

\begin{tabular}{c|c|c|c}
\hline Total investimentos & Transporte & $\begin{array}{c}\text { Trituração e valoração } \\
\text { energética }\end{array}$ & $\begin{array}{c}\text { Granulação, laminação e extração } \\
\text { aço }\end{array}$ \\
\hline $\mathbf{6 3 , 6 0}$ & 36,60 & 16,50 & 10,50 \\
\hline
\end{tabular}

Nota. Distribuição dos investimentos da ANIP em atividades de coleta e reaproveitamento de pneus em 2011.

Fonte: Adaptado de Confederação Nacional da Indústria (2014). Proposta de implementação dos instrumentos econômicos previstos na lei $n^{\circ} 12.305 / 2010$ por meio de estímulos à cadeia de reciclagem e apoio aos setores produtivos obrigados à logística reversa.

TABELA 2 - Principais destinações dos resíduos de pneus inservíveis no Brasil

\begin{tabular}{l|c|c}
\hline Formas de destinação & Valor Gasto (MI de R\$) & $\%$ de Destinação \\
\hline Trituração e valorização energética & $16.482,05$ & $67,1 \%$ \\
\hline Granulação, laminação e extração de aço & $10.460,04$ & $32,9 \%$ \\
\hline Pisos e gramados & & $6,5 \%$ \\
\hline Artefatos de borracha & & $8,0 \%$ \\
\hline Asfalto & & $2,0 \%$ \\
\hline Construção civil & & $1,5 \%$ \\
\hline Siderurgia & & $7,0 \%$ \\
\hline Laminação & & $7,9 \%$ \\
\hline Total & $\mathbf{2 6 . 9 4 2 , 0 9}$ & $\mathbf{1 0 0 , 0} \%$ \\
\hline
\end{tabular}

Nota. A tabela apresenta um resumo das principais tecnologias utilizadas na reciclagem ou reaproveitamento de pneus no Brasil. Fonte: Adaptado de Confederação Nacional da Indústria (2014). Proposta de implementação dos instrumentos econômicos previstos na lei $n^{\circ} 12.305 / 2010$ por meio de estímulos à cadeia de reciclagem e apoio aos setores produtivos obrigados à logística reversa. 
um método muito importante para identificar o risco de investimento de um projeto, se em determinado projeto a taxa interna de retorno for maior que a taxa de aplicação, o projeto será aceitável. Em síntese os valores apresentados podem ser interpretados conforme os seguintes critérios de análise:TIR maior que a TMA se aceita o projeto.

O Valor Presente Líquido - VPL calcula o valor do dinheiro no tempo, como descreve Gitman (2010, p.369), é uma técnica sofisticada de orçamento de capital, é calculado subtraindo-se o investimento inicial do valor presente das entradas de caixa do projeto, sendo essa descontada a taxa de custo de capital da empresa", assim permitindo comparação entre o investimento inicial com os retornos futuros. Quanto a VPL, o critério de análise é que este uma vez positivo devese aceitar o projeto, para este caso, o projeto satisfaz a condição requerida.

Por fim o Payback, refere-se ao período de tempo em que os resultados do projeto se equiparam ao investimento inicial. Para Gitman (2010, p. 366), “o período payback é o tempo necessário para que a empresa recupere o investimento inicial em um projeto, calculado a partir das entradas de caixa".

Diante do contexto aqui discutido, o presente estudo elencou uma série de procedimentos metodológicos para investigar como está sendo tratada a questão da destinação de pneus no Brasil e do Mun- do, além de se verificar o perfil ambiental dos consumidores de pneus agrícolas, bem como analisar a viabilidade econômica e financeira para a implantação de uma usina recicladora de pneus agrícolas.

$\mathrm{Na}$ seção a seguir, são apresentadas as informações referentes à pesquisa realizada com os agricultores, clientes da empresa objeto de estudo.

\section{Procedimentos Metodológicos}

A metodología utilizada investigou-se a percepção ambiental dos consumidores de pneus agrícolas, além da viabilidade econômica e financeira de implementação de uma usina recicladora para uma empresa de recauchutagem de pneus agrícolas. Nesta seção será exposto o modelo de mensuração dos dados utilizado no estudo, bem como modelo para avaliação da consciência ambiental dos agricultores objeto de estudo.

\section{Avaliação do perfil do consumidor}

Elias et al. (2013) conceberam um modelo de análise quantitativa descritiva para medir a moderação do nível de confiança dos consumidores na relação entre consciência ambiental e intenção de consumo ambiental (Figura I).

O questionário utilizado foi estruturado em quatro seções: a primeira objetivando identificar os dados sociodemográficos dos respondentes (sexo, renda familiar, idade,

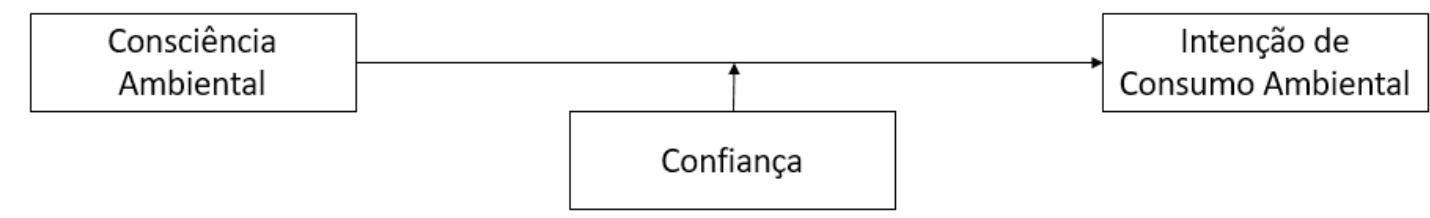

FIGURA 1 - Modelo Conceitual

Fonte: Elias et al. (2013), pg. 58. 
nível de escolaridade); a segunda com as 15 afirmativas da escala NEP (New Ecological Paradigm Scale), validada no contexto brasileiro por Silva Filho et al. (20I0), para a mensuração da consciência ambiental; a terceira para mensuração da escala ICA (Intenção de Consumo Ambiental) com nove itens, que foi elaborada com base na Environmental Behaviors Scale de Kilbourne e Pickett (2008), composta por nove itens, bem como na escala de comportamento ambiental do estudo de Braga Junior, Silva, Moretti e Lopes (20I2); e a quarta seção contemplando os oito itens da escala de confiança, mensurada pela escala de Doney e Cannon (1997), traduzida e validada no Brasil por Frederico e Robic (2008), composta por oito itens, que engloba as dimensões de credibilidade e benevolência. Todos os itens foram mensurados por meio da escala numérica de Likert de I (discordo totalmente) a 5 (concordo totalmente) pontos.

Quanto à técnica de análise, os dados foram tratados pelos autores por meio da análise fatorial confirmatória (AFC), conforme a metodologia de Anderson e Gerbing (1988), realizada em duas etapas: a primeira, buscando identificar a validade de convergência dos constructos; na segun- da, foram analisadas as relações entre os construtos latentes. $\mathrm{O}$ efeito moderador da confiança foi testado por uma análise de grupos múltiplos, que permitiu uma comparação intergrupos.

Todos os coeficientes estimados foram significativos a um nível de $0,1 \%$ de significância, para os três modelos estruturais, demonstrando que existe relação entre consciência ambiental e intenção de consumo ambiental. Como resultado, Elias et al. (20I3) chegaram a um modelo de mensuração (Figura 2), que representa o modelo referente ao teste das validades discriminantes e convergentes dos construtos estudados. Percebe-se, com ele, que vários itens da escala foram retirados, dentre eles os seis itens da anti-NEP que não se ajustaram ao modelo por não terem sido compreendidos pelos respondentes.

Como hipóteses a serem validadas no presente estudo, por meio da regressão linear com fator moderador, foram elencadas as seguintes: $\mathbf{H}_{1}$ : A consciência ambiental está positivamente relacionada com a intenção de consumo ambiental. Apesar da relação proposta entre a consciência ambiental e o consumo, Frederico, Queve-

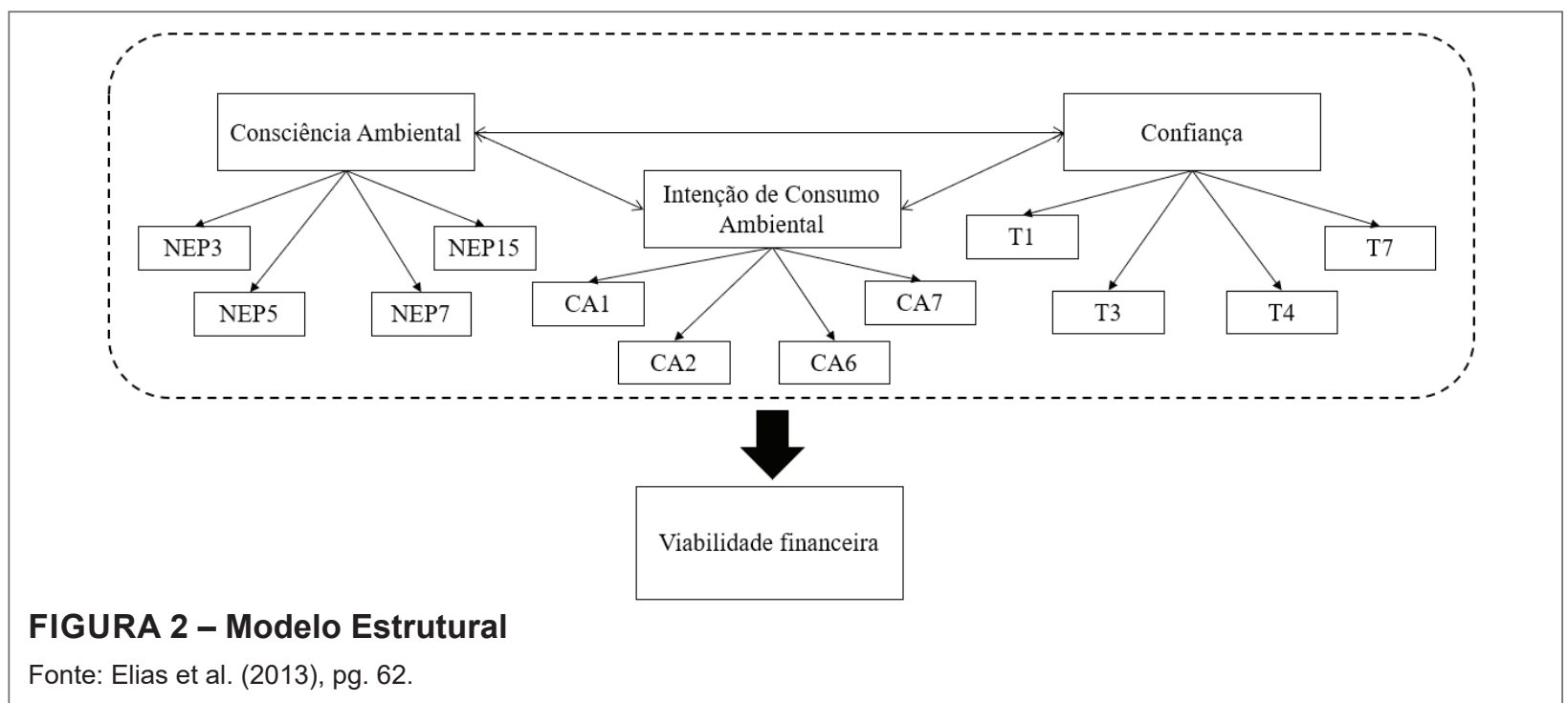


do-Silva, ; Freire (2013) afirmam que muitos estudos têm identificado um gap entre o discurso do consumidor e a prática, ou seja, mesmo aquele consumidor identificado como tendo consciência ambiental elevada, por vezes não demonstra interesse em praticar o consumo ambiental. $\mathbf{H}_{2}: \mathrm{O}$ efeito moderador da confiança nas empresas que se afirmam ecologicamente corretas ou sustentáveis está positivamente relacionado com a consciência e intenção de consumo ambiental.

Neste contexto este estudo avalia se a confiança do consumidor na empresa modera sua decisão de consumo ambiental. Sob esta ótica seria possível, uma vez confirmada a hipótese, afirmar que a confiança na entidade empresarial, influencia positivamente a intenção de consumo ambiental. As análises foram realizadas utilizando o software IBM SPSS 23.

Com base nas informações coletadas por meio dos questionários, a etapa seguinte do estudo foi a realização da confirmação das hipóteses por meio da utilização do método de Regressão Linear com a utilização de uma variável moderadora, por se apresentar como uma solução robusta para a compreensão das relações existentes entre as variáveis objeto de estudo (VIEIRA; FAIA 20I4).

A regressão foi executada utilizando o modelo hierárquico, no qual foram definidos dois blocos: no primeiro (modelo I) foram testadas as variáveis consciência ambiental ( $x$ - variável independente) em relação à intenção de consumo ambiental ( $y$ - variável dependente); no segundo bloco (modelo 2), foram testadas as variáveis consciência ambiental (xI - variável independente), confiança (x2 variável independente) e intenção de consumo ambiental ( $y$ - variável dependente). A variável confiança, inserida no modelo 2 , teve como objetivo verificar se a presença da confiança na relação com empresas que afirmam serem sustentáveis teria influência positiva na intenção de consumo ambiental, por meio de uma melhor explicação do modelo.

\section{Viabilidade econômica e financeira de implantação de uma Usina de Re- ciclagem}

Com objetivo de apoiar o empreendeor na descisão de auferir ganhos com o descarte de pneus inservíveis e fragmentos originados do processo de recalchutagem, foi conduzido um estudo de viabilidade econômica e financeira para implementação da usina de reciclagem de pneus. Conforme Lagarinhos e Tenório (2012), uma usina de reciclagem (recicladora) é a empresa que tritura e granula os pneus inservíveis, separando o aço e as fibras têxteis utilizadas na construção dos pneus, com produto final pó de borracha e aço.

Para determinação do investimento, estimatimativa de produtividade, faturamento, bem como a estimativa de custos fixos e resultados, foram realizados por meio da adaptação do modelo proposto por Bertolini (2009), cujo objetivo é permitir ao pesquisador avaliar a viabilidade de produtos ambientalmente corretos e sustentáveis.

\section{Caracterização da Empresa}

A Dal Molin Recauchutagem de Pneus Agrícolas está localizada na Av. Brasil, 538 Aroeira, Cascavel - PR, desde sua inauguração em 1986. Dentre os valores institucionais, elenca o respeito ao meio ambiente e descreve como parte de sua missão institucional o desenvolvimento sustentável.

A empresa mantém parceria com recicladoras licenciadas para onde envia $100 \%$ 
de seus resíduos oriundos da reforma dos pneus (aparas e pneus inservíveis). Em sua produção somente utiliza energia - madei$\mathrm{ra}$ - oriunda de fontes licenciadas pelo IAP (Instituto Ambiental do Paraná). Há alguns anos a empresa tem investido em reflorestamento próprio de eucalipto visando à sustentabilidade do negócio.

Atualmente, a associação de empresas de recauchutagem de pneus da qual a Dal Molin Pneus Ltda é associada, fica responsável pela destinação final dos pneus inservíveis. Além dos pneus inservíveis, o processo de recondicionamento dos pneus agrícolas gera aproximadamente 25 toneladas mensais de resíduos de borracha, entre pó e aparas.

\section{RESULTADOS}

Com o presente estudo, foi possível verificar que o esforço direcionado para a busca de alternativas viáveis de destinação sustentável de pneus inservíveis se fundamenta pela crescente produção de pneus, que impactam negativamente no meio ambiente, quando destinados incorretamente.

Com efeito, foram idealizadas normativas internacionais e nacionais que exigem adequação das empresas que não possuem como mister zelar pelo meio ambiente. Após reunir todas as informações e dados com $\circ$ presente estudo, discorrem-se os resultados verificados no contexto da destinação sustentáveis de pneus agrícolas.

\section{Avaliação da consciência e consumo ambiental sustentável}

Com base nos dados obtidos por meio dos questionários, pode-se traçar o perfil dos agricultores, clientes da empresa Dal Molin Recauchutagem de Pneus Agrícolas, além de testar a influência da variável confiança na intenção de consumo ambiental da amostra pesquisada, conforme demonstrado nas subseções a seguir.

Os participantes da pesquisa representaram um total de 160 dos 7000 clientes da Dal Molin Recauchutagem de Pneus Agrícolas. Desse total, 55\% foram homens, tendo a maioria deles idade entre 35 e 49 anos de idade $(21,88 \%)$, e $45 \%$ mulheres, cuja faixa etária predominante esteve acima dos 50 anos.

Os 160 agricultores responderam ao questionário composto por 35 questões, sendo 32 delas relacionadas à consciência ambiental, confiança e intenção de consumo ambiental, e as demais referentes à questão socioeconômica.

Os dados obtidos por meio da análise das respostas estão descritos na seção a seguir.

\section{Análises descritivas}

A análise do constructo consciência ambiental pode ser realizada por meio da avaliação das variáveis que o compõem (Tabela 3).

Considerando-se a média da variável NEP3 - Quando os seres humanos interferem

TABELA 3 - Análise do constructo consciência ambiental

\begin{tabular}{l|c|c|c|c|c|c}
\hline \multicolumn{7}{c}{ Consciência Ambiental } \\
\hline Variáveis & $\mathbf{1}$ & $\mathbf{2}$ & $\mathbf{3}$ & $\mathbf{4}$ & $\mathbf{5}$ & Média \\
\hline NEP3 & $20,6 \%$ & $39,4 \%$ & $18,1 \%$ & $18,9 \%$ & $3,1 \%$ & 2,44 \\
\hline NEP5 & $30,6 \%$ & $48,8 \%$ & $14,4 \%$ & $5,6 \%$ & $0,6 \%$ & 1,97 \\
\hline NEP7 & $41,9 \%$ & $36,3 \%$ & $17,5 \%$ & $4,4 \%$ & $0,0 \%$ & 1,84 \\
\hline NEP15 & $25,6 \%$ & $41,9 \%$ & $19,4 \%$ & $8,8 \%$ & $4,4 \%$ & 2,24
\end{tabular}

Nota. A tabela apresenta os percentuais de respostas para cada item da escala Likerd, para as variáveis que compõem o constructo da consciência ambiental. É apresentada também a coluna contendo o valor da média obtida a partir das respostas de cada uma das questões. Fonte: Dados da pesquisa (2017). 
na natureza, se produz frequentemente consequências desastrosas, foi possível concluir que os entrevistados não acreditam que suas ações podem produzir danos irreparáveis ao meio ambiente. Da mesma forma, ao se analisar as variáveis NEP5 - Os seres humanos estão abusando seriamente do meio ambiente e NEP7 - Plantas e animais têm tanto direito de existir quando os seres humanos, pode-se concluir que os agricultores pesquisados não se preocupam com as relações entre os seres humanos e a natureza e não acreditam que as suas ações possam, de fato, provocar a destruição dos recursos naturais. Por fim, com o resultado obtido na análise da variável NEPI5 - Se as coisas continuarem no curso atual, nós iremos em breve experimentar uma catástrofe ecológica maior, foi possível identificar a ausência de preocupação, por parte dos respondentes, com a mudança de atitudes consideradas nocivas ao meio ambiente.

Em relação á intenção do consumo ambiental, as variáveis analisadas foram CAI -
Sempre que possível, eu compro produtos ecologicamente corretos, CA2 - Sempre que possível, eu compro alimentos orgânicos, CA6 - Pagaria mais para comprar produtos orgânicos e CA7 Já busquei informações de como poderia ajudar a diminuir a poluição (Tabela 4).

Com base nos valores obtidos, foi possível observar que os entrevistados sequer buscaram informações relacionadas ao consumo sustentável, e que não costumam dar preferência a produtos classificados como orgânicos ou ambientalmente corretos.

Por fim, o constructo confiança nas empresas que se dizem ambientalmente corretas foi analisado por meio das variáveis TI - Empresas sustentáveis são confiáveis, T3 - Quando tomam decisões importantes, as empresas sustentáveis também olham o lado do consumidor, T4 - Empresas sustentáveis se preocupam com nossas prioridades e T7 Empresas sustentáveis são genuinamente preocupadas com os consumidores (Tabela 5).

Conforme pode ser observado nas médias obtidas em cada uma das variáveis, os

TABELA 4 - Análise do constructo intenção de consumo ambiental

\begin{tabular}{c|c|c|c|c|c|c}
\hline \multicolumn{7}{c}{ Intensão de Consumo Ambiental } \\
\hline Variáveis & $\mathbf{1}$ & $\mathbf{2}$ & $\mathbf{3}$ & $\mathbf{4}$ & $\mathbf{5}$ & Média \\
\hline CA1 & $23,1 \%$ & $50,6 \%$ & $21,3 \%$ & $3,8 \%$ & $1,3 \%$ & 2,09 \\
\hline CA2 & $20,6 \%$ & $40,6 \%$ & $25,0 \%$ & $12,5 \%$ & $1,3 \%$ & 2,33 \\
\hline CA6 & $18,8 \%$ & $42,5 \%$ & $25,6 \%$ & $10,6 \%$ & $2,5 \%$ & 2,35 \\
\hline CA7 & $21,3 \%$ & $43,1 \%$ & $20,0 \%$ & $13,8 \%$ & $1,9 \%$ & 2,39 \\
\hline
\end{tabular}

Nota. A tabela apresenta os percentuais de respostas para cada item da escala Likerd, para as variáveis que compõem o constructo da consciência ambiental. É apresentada também a coluna contendo o valor da média obtida a partir das respostas de cada uma das questões. Fonte: Dados da pesquisa (2017).

TABELA 5 - Análise do constructo confiança

\begin{tabular}{c|c|c|c|c|c|c}
\hline \multicolumn{7}{c}{ Confiança } \\
\hline Variáveis & $\mathbf{1}$ & $\mathbf{2}$ & $\mathbf{3}$ & $\mathbf{4}$ & $\mathbf{5}$ & Média \\
\hline T1 & $15,6 \%$ & $25,6 \%$ & $40,0 \%$ & $16,3 \%$ & $2,5 \%$ & 2,64 \\
\hline T3 & $10,0 \%$ & $26,3 \%$ & $33,8 \%$ & $25,0 \%$ & $5,0 \%$ & 2,89 \\
\hline T4 & $6,3 \%$ & $21,9 \%$ & $33,8 \%$ & $33,8 \%$ & $4,4 \%$ & 3,08 \\
\hline T7 & $3,8 \%$ & $20,6 \%$ & $40,0 \%$ & $32,5 \%$ & $3,1 \%$ & 3,11 \\
\hline
\end{tabular}

Nota. A tabela apresenta os percentuais de respostas para cada item da escala Likerd, para as variáveis que compõem o constructo da consciência ambiental. É apresentada também a coluna contendo o valor da média obtida a partir das respostas de cada uma das questões. Fonte: Dados da pesquisa (2017). 
agricultores apresentaram certa indiferença em relação às políticas adotadas pelas empresas que se dizem ambientalmente corretas, não expressando total crença na demonstração de preocupação expressa por essas empresas em relação ao meio ambiente. Isso pode ser um indício de que há pouca ou nenhuma confiança nessas empresas ou em suas políticas.

\section{Análise de correlação}

Por meio da análise de correlação entre as variáveis, foram testadas as hipóteses de pesquisa $\mathrm{H}_{1}$ e $\mathrm{H}_{2}$. A partir da Regressão Linear Múltipla, por meio da análise de correlações, foi possível identificar que, tanto a consciência ambiental quanto a confiança possuem correlação positiva com a intenção de consumo. Entretanto, a correlação é fraca $(\rho=0,288$ e $\rho=0,343)$, o que índica pouca influência de ambas as variáveis sobre a intenção de consumo ambiental. Tomando como base os valores de médias obtidos na análise descritiva do constructo consciência ambiental, pode-se concluir que a amostra pesquisada não pode ser caracterizada como ambientalmente consciente.

Considerando os valores de $\mathrm{R}^{2}$ para os dois modelos, o modelo 2 apresentou maior capacidade de explicação $\left(R^{2}=\right.$ $10,6 \%$ ) da variação da variável intenção de consumo, em relação ao modelo I $\left(\mathrm{R}^{2}=\right.$ $7,7 \%$ ), o que indica que a confiança possui impacto na intenção de consumo ambiental da amostra pesquisada.

Com base no teste F, foi possível concluir que a inclusão da variável consciência ambiental no modelo I $(\rho=0,000)$, e a inclusão das variáveis consciência ambiental e confiança no modelo $2(\rho=0,0 \mid 4)$ tornaram o modelo melhor em relação à média. Conforme observado nos valores de $\rho$, ambos os modelos são estatisticamente significantes, embora o modelo 2 tenha meIhor capacidade de explicação da variável y. Ainda que o modelo 2 tenha apresentado melhoria no percentual de explicação, fica evidente a necessidade de aprofundamento dos estudos e inclusão de outras variáveis que possibilitem uma melhor explicação do fenômeno.

De modo a validar a significância dos modelos em relação a um modelo sem as variáveis previsoras, verificou-se os resultados obtidos por meio do teste da Anova. Considerando o $\rho<0,05$ em ambos os casos, foi possível afirmar que, tanto o modelo I quanto o modelo 2 são estatisticamente significantes, o que permite afirmar que os mesmos são melhores do que um modelo sem as variáveis previsoras consciência ambiental e confiança. Além disso, foi possível concluir, portanto, que a consciência ambiental e a confiança são previsoras da intenção de consumo ambiental dos agricultores, entretanto, a variável consciência ambiental possui maior peso para o modelo $(\beta=0,266)$ do que a variável confiança $(\beta=0,187)$.

As hipóteses $\mathrm{H}_{1}$ e $\mathrm{H}_{2}$ foram confirmadas, ou seja, a consciência ambiental está correlacionada com a intenção de consumo e, sob influência da variável confiança, a correlação foi confirmada. Além disso, a inclusão da variável confiança melhorou a capacidade de explicação do modelo, embora haja a recomendação de que outros estudos possam incluir outras variáveis que proporcionem maior poder de explicação ao modelo. Apesar dos resultados levantados com os agricultores em relação a consciência e consumo ambiental sustentável, a seguir são apresentados os cálculos financeiros sobre uma usina de reciclagem de pneus inservíveis. 


\section{Viabilidade econômica e financeira Usina Reciclagem de Pneus Inservíveis}

No presente estudo, percebeu-se que nos últimos 05 anos a temática "destinação de pneus inservíveis" foi intensificada. Apesar do aumento nas pesquisas, não foram encontradas nos estudos nacionais $e$ internacionais abordados neste trabalho, referências que tratassem especificamente de resultados econômicos e financeiros dos pneus agrícolas. Estes pneus apresentam características bastante particulares, incluindo tamanho, peso e composição, o que faz com que haja a necessidade de realização de estudos específicos e com maior nível de aprofundamento.

Vários estudos científicos na área de engenharia e logística foram realizados e, em grande parte deles, foram apresentadas alternativas criativas e lucrativas para a destinação sustentável de pneus inservíveis. Dentre as técnicas que mais reutilizam os pneus inservíveis como matéria prima, destacam-se as apresentadas na área da construção civil e da confecção de manta asfáltica. Em todos os processos, a reutilização dos pneus inservíveis se dá após sua trituração e transformação em pó, que é reutilizado junto a outros produtos para a produção de argamassas, cimentos, asfalto, Xisto, artefatos de borracha, dentre outros.

\section{INVESTIMENTO TOTAL}

O projeto foi estruturando levando em consideração verbas originadas de financiamento e incentivos bancários, onde o investidor deve entrar com uma parcela de capital próprio que deverá ser de até $20 \%$ do investimento total do valor da usina completa e garantias bancárias. Os valores foram considerados para fins de investimento (Tabela 6).

\section{Estimativa de produtividade e faturamentos}

Para efeitos de determinação do volume de produção da usina foram considerados as variáveis elencadas na Tabela 7 .

Após determinado o volume de horas de produção por ano de atividade, determinouse com base na capacidade da máquina os volumes de matéria prima necessários para

TABELA 6 - Investimento total usina reciclagem de pneus

\begin{tabular}{l|c}
\hline & Vlr \\
\hline Máquina completa (Modelo CP-500 kg/hora) & $1.550 .443,00$ \\
\hline Estrutura física comporta usina & $310.088,00$ \\
\hline Engenharia e montagem & $149.340,00$ \\
\hline Capital giro & $100.000,00$ \\
\hline Investimento pré-operacional & $5.000,00$ \\
\hline Total investimento inicial & $\mathbf{2 . 1 1 4 . 8 7 1 , 0 0}$ \\
\hline
\end{tabular}

Fonte: Dados da pesquisa (2017)

TABELA 7 - Cálculo da produtividade da usina

\begin{tabular}{l|c}
\hline Produtividade & Vlr absolutos \\
\hline Meses de operação no ano & 12 \\
\hline Dias de operação por mês & 21 \\
\hline Horas produção por dia de operação & 16 \\
\hline Tempo produção mês/h & $\mathbf{3 3 6}$ \\
\hline Tempo produção ano & $\mathbf{4 . 0 3 2}$ \\
\hline
\end{tabular}

Fonte: Dados da pesquisa (2017) 
operar a usina, buscando otimizar e explorar seu completo potencial produtivo (Tabela 8).

Com referência nas informações do fornecedor do equipamento, foi possível calcular com base nos rendimentos e mix de produtos, os volumes de produção, a partir do volume de matéria prima processada por mês demonstrado acima (Tabela 9).

Levando em consideração os preços de venda dos produtos originados, seguem os valores prováveis de faturamento bruto mensal que poderá ser auferido pela indústria, considerando a venda total da produção originada (Tabela I0).

\section{Estimativa dos custos fixos operacionais}

Os custos fixos operacionais referem-se aos desembolsos mensais que a empresa deverá realizar para sustentar suas atividades de produção e venda (Tabela II).

\section{Estimativa de resultados e cálculos (TIR,VPL e Payback)}

Após determinadas as estimativas de produção, faturamentos e custos operacionais foi possível elaborar uma DRE - Demonstrativo do resultado do exercício, simplificada aferindo o fluxo de caixa anual do projeto (Tabela I2).

Por fim, calculou-se os indicadores de viabilidade TIR (Taxa Interna de Retorno), VPL (Valor Presente Líquido) e Payback no intuito de obter uma indicação de viabilidade do empreendimento. Foram obtidos os dados referenciados nas Tabelas I3, 14 e I5 respectivamente. Para os cálculos de VPL e Payback descontado foi utilizado a taxa referencial Selic $(9,25 \%)$ para TMA. Os fluxos de caixa foram corrigidos anualmente pela inflação estimada de $4,5 \%$ ao ano.

O horizonte de análise calculado foi de 10 anos, conforme o período de depreciação

TABELA 8 - Capacidade de processamento matéria prima

\begin{tabular}{l|c|c}
\hline \multicolumn{1}{c|}{ Item } & Volume & Escala \\
\hline Capacidade produção máquina & 500 & $\mathrm{Kg} / \mathrm{h}$ \\
\hline Volume processamento diário & 8.000 & $\mathrm{Kg} / \mathrm{d}$ \\
\hline Volume processamento mês 21 dias uteis & 168.000 & $\mathrm{Kg} / \mathrm{m}$ \\
\hline
\end{tabular}

Fonte: Dados da pesquisa (2017)

TABELA 9 - Rendimentos e mix de produtos

\begin{tabular}{l|c|c|c}
\hline \multicolumn{1}{c|}{ Mix produção (Informações importador) } & Rendimentos & Mix & Kg/mês \\
\hline $70 \%$ da matéria prima (P1-Borracha 30mm) & 0,70 & Pó borracha & 117.600 \\
\hline $16 \%$ da matéria prima (P2-Nylon) & 0,16 & Fibras têxteis & 26.880 \\
\hline $12 \%$ da matéria prima (P3-Limalha aço) & 0,12 & Aço fragmentado & 20.160 \\
\hline $2 \%$ da matéria prima (Quebra técnica) & 0,02 & Resíduo & 3.360 \\
\hline
\end{tabular}

Nota. Volumes por mix de produto.

Fonte: Dados da pesquisa (2017)

TABELA 10 - Estimativa de volumes de produção e faturamento

\begin{tabular}{|c|c|c|c|c|c|c|c|}
\hline Produto & $\begin{array}{l}\text { Kg por } \\
\text { hora }\end{array}$ & $\begin{array}{c}\text { Kg por } \\
\text { dia }\end{array}$ & Kg mês & $\begin{array}{c}\text { Preço de } \\
\text { venda por } \\
\mathrm{Kg}\end{array}$ & $\begin{array}{l}\text { Preço de } \\
\text { venda por } \\
\text { Ton. }\end{array}$ & $\begin{array}{c}\text { Faturamento } \\
\text { total dia }\end{array}$ & $\begin{array}{l}\text { Faturamento } \\
\text { total mês }\end{array}$ \\
\hline Pó Borracha & 350 & 5.600 & 117.600 & 1,17 & $1.170,00$ & $6.552,00$ & $137.592,00$ \\
\hline Nylon & 80 & 1.280 & 26.880 & 1,33 & $1.330,00$ & $1.702,40$ & $35.750,40$ \\
\hline Limalha aço & 60 & 960 & 20.160 & 2,33 & $2.330,00$ & $2.236,80$ & $46.972,80$ \\
\hline Total/mês & 490 & 7.840 & 164.640 & & & $10.491,20$ & $220.315,20$ \\
\hline
\end{tabular}

Fonte: Dados da pesquisa (2017) 
TABELA 11 - Despesas operacionais mensais

\begin{tabular}{l|c}
\hline Despesas mensais & Valores (R\$) \\
\hline Parcelas empréstimo & $51.742,00$ \\
\hline Depreciação & $14.212,39$ \\
\hline IPTU & $2.000,00$ \\
\hline Água & 270,00 \\
\hline Energia elétrica & $12.000,00$ \\
\hline Telefone & 350,00 \\
\hline Serviços de natureza contábil e tributária & 978,00 \\
\hline Pró-labore & $8.000,00$ \\
\hline Manutenção dos equipamentos & $2.000,00$ \\
\hline Salários + encargos & $8.500,00$ \\
\hline Material de limpeza & 300,00 \\
\hline Material de escritório & $1.800,00$ \\
\hline Combustível & $4.540,00$ \\
\hline Taxas diversas & $1.100,00$ \\
\hline Total & $107.792,39$ \\
\hline
\end{tabular}

Fonte: Dados da pesquisa (2017)

TABELA 12 - Demonstrativo resultado do exercício simplificada

\begin{tabular}{l|c}
\hline DRE simplificada & VIr. R\$ \\
\hline (+) Receitas com vendas & $2.643 .782,40$ \\
\hline (-) Custos transportes (6\% s/ Vendas) & $(158.626,94)$ \\
\hline (-) Despesas operacionais & $(1.293 .508,70)$ \\
\hline (-) Despesas com vendas & $(57.600,00)$ \\
\hline (+) Resultado operacional bruto & $\mathbf{1 . 1 3 4 . 0 4 6 , 7 6}$ \\
\hline
\end{tabular}

Fonte: Dados da pesquisa (2017)

das máquinas componentes da usina, porem vista que é o suficiente para as conclusões foram apresentados os primeiros 5 anos haja requeridas, dado ao rápido retorno.

TABELA 13 - Cálculos de VPL (Valos presente líquido) e TIR (Taxa interna de retorno)

\begin{tabular}{l|r|r|r|r|r|r}
\hline \multicolumn{1}{c|}{ Ano } & \multicolumn{1}{c|}{$\mathbf{0}$} & \multicolumn{1}{c|}{$\mathbf{1}$} & \multicolumn{1}{c|}{$\mathbf{2}$} & $\mathbf{3}$ & $\mathbf{4}$ & $\mathbf{5}$ \\
\hline Fluxo caixa final & $(2.114 .871)$ & 1.134 .047 & 1.185 .079 & 1.238 .407 & 1.294 .136 & 1.352 .372 \\
\hline Fluxo caixa acumulado & $(2.114 .871)$ & $(980.824)$ & 204.255 & 1.442 .662 & 2.736 .798 & 4.089 .170 \\
\hline Fluxo caixa descontado & $(2.114 .871)$ & 1.038 .029 & 992.897 & 949.728 & 908.435 & 868.938 \\
\hline F. Caixa descontado acumulado & $(2.114 .871)$ & $(1.076 .842)$ & 83.945 & 865.783 & 1.774 .219 & 2.643 .157 \\
\hline VPL & $\mathbf{2 . 6 4 3 . 1 5 7}$ & & & & & \\
\hline TIR & $\mathbf{4 9 , 0 3 \%}$ & & & & & \\
\hline
\end{tabular}

Fonte: Dados da pesquisa (2017)

TABELA 14 - Fluxos de caixa para Cálculos de Payback

\begin{tabular}{l|c|c|c|c|c|c}
\hline Variável/Ano & Ano 0 & Ano 1 & Ano 2 & Ano 3 & Ano 4 & Ano 5 \\
\hline Investimento & $(2.114 .871)$ & & & & & \\
\hline Lucro nominal (FV) & & 1.134 .047 & 1.185 .079 & 1.238 .407 & 1.294 .136 & 1.352 .372 \\
\hline Valor presente (PV) & & 1.038 .029 & 992.897 & 949.728 & 908.435 & 868.938 \\
\hline Saldo investimento & $(2.114 .871)$ & $(1.076 .842)$ & $(83.945)$ & 865.783 & 1.774 .219 & 2.643 .157 \\
\hline
\end{tabular}

Fonte: Dados da pesquisa (2017) 
TABELA 15 - Demonstrativo de Payback

\begin{tabular}{l|c}
\hline Payback descontado & VIr \\
\hline Investimento inicial & 2.114 .871 \\
\hline Receita anual prevista & 2.643 .782 \\
\hline Despesa anual prevista & 1.509 .736 \\
\hline Lucro anual previsto & 1.134 .047 \\
\hline Taxa (TMA) & $9,25 \%$ \\
\hline Payback descontado (anos) & $\mathbf{1 , 8 4}$ \\
\hline
\end{tabular}

Fonte: Dados da pesquisa (2017)

Cabe ressaltar que a capacidade de produção e venda da usina devem estar utilizando toda a capacidade do empreendimento.

\section{DISCUSSÕES}

Quanto ao universo de agricultores, clientes da empresa Dal Molin Recauchutagem de Pneus Agrícolas, os resultados obtidos apontam que, embora as hipóteses de pesquisa $\mathrm{HI}$ e $\mathrm{H} 2$ tenham sido confirmadas, o cliente desta empresa não se preocupam com a relação existente entre os seres humanos e a natureza, tampouco acreditam nas organizações que explicitam se preocuparem com um ambiente sustentável.

Tendo em vista que a empresa elenca entre seus valores e visão a continuidade de suas atividades de maneira sustentável e sem impactos negativos ao meio ambiente, tais informações são relevantes, uma vez que emerge para o corpo gerencial da Dal Molin buscar formas de conscientização dos seus consumidores, sob pena de seu propósito de atuar com sustentabilidade perecer.

Como é sabido que há relação positiva entre a intenção de consumo ambiental e a consciência ambiental, buscar estratégias de se conscientizar o cliente é uma maneira de fidelização, aumento do consumo e perpetuação das atividades da empresa em estudo no mercado competitivo. Conforme afirmam Brandalise et al. (2015) e Kim e Mauborgne (2005), esta postura proposta levaria a Dal Molin pneus a ter vantagem competitiva por ser a empresa do ramo pioneira em ações desta natureza, ao se manifestar ativa no âmbito da sustentabilidade ambiental, preocupando-se não apenas com os resultados imediatos de suas ações.

Já com relação à viabilidade para implantação de uma usina de reciclagem de pneus inservíveis e aparas de borracha, identificou-se que a atividade de reciclagem é viável e lucrativa, porem requer que a capacidade de processamento da usina esteja operando sempre de maneira otimizada.

Os resultados encontrados no estudo de viabilidade convergem com resultados obtidos pelo estudo de Silva e Damo (2016), que utilizou a análise de cenários como método e identificou que, mesmo o cenário pessimista, pôde-se constatar que seria viável a implantação de uma usina de reciclagem de pneus no município de Ma$\mathrm{rau} / \mathrm{MS}$. Desta forma, além de prover uma destinação adequada para os resíduos, a usina traz retornos financeiros ao investidor dentro de um curto período de tempo.

Dentre as principais contribuições do estudo destaca-se a análise da relação entre a consciência ambiental e a intenção de consumo ambiental, que se mostrou positiva para os agricultores objeto do estudo, bem como a alternativa de reciclagem por coprocessamento que, se empreendida, trará efeitos positivos para a imagem da empresa, além de se tornar uma fonte de receitas para diversificação e sustentabili- 
dade no âmbito econômico, social e ambiental, conforme o triple botton line proposto por Elkington (1997).

Para Kraemer (2005), a geração de valor com base na proposta de Elkington (1997) deve ser contemplada nas estratégias adotadas pelas empresas que pretendem perenizar seus negócios e se manterem ativas em um mercado cada vez mais dinâmico.

É relevante ressaltar que são raros os estudos que avaliam a viabilidade econômica da implementação de novas alternativas relacionadas à destinação correta dos pneus e resíduos, considerando que grande parte das pesquisas tratam apenas da viabilidade técnica. Tal avaliação é de fundamental importância para garantir que toda a demanda de processamento de um número crescente de pneus seja atendida de forma eficaz, evitando prejuízos ao meio ambiente, e à sociedade, no sentido de minimizar os riscos de proliferação de determinadas doenças ocasionadas com a degradação do meio ambiente

Sob a perspectiva social, a implantação de usinas de reciclagem de pneus pode se tornar uma fonte de renda para diversas famílias, considerando que há a necessidade de operadores para as máquinas e estas, por sua vez, devem estar em operação diariamente em vários turnos.

\section{CONCLUSÕES}

A revisão de literatura possibilitou concluir que a discussão sobre a questão dos pneus inservíveis tem sido amplamente discutida no cenário mundial. No Brasil, grande parte das ações realizadas tem como protagonista a ANIP, a qual, por meio da Reciclanip, tem buscado não apenas a destinação correta, mas também o combate à importação ilegal de pneus para o país.
No que se refere à intenção de consumo ambiental dos agricultores, foi possível confirmar as hipóteses de pesquisa testadas. Desta forma, concluiu-se que o nível de consciência ambiental dos agricultores tem influência positiva sobre a intenção de consumo ambiental. Quando moderada pelo efeito da variável confiança, a relação entre a consciência e a intenção de consumo permaneceu, demonstrando a influência positiva da confiança dos agricultores nas empresas que se afirmam ambientalmente corretas.

Já os agricultores da empresa objeto de estudo não apresentam nem consciência ambiental nem preocupação com a sustentabilidade ambiental significativas, revelando que emerge a necessidade da empresa em se preocupar com a busca por estratégias de conscientização ambiental dos seus consumidores, visando sua perpetuação das suas atividades de maneira sustentável no mercado competitivo, além de garantir vantagem competitiva em relação aos seus concorrentes.

Entretanto, sob a perspectiva da viabilidade de implantação de uma usina de reciclagem, o estudo evidenciou que a atividade de reciclagem é viável e lucrativa, pois há um mercado próprio para a sua destinação e geração de receitas, não dependendo dos clientes da organização. Desta forma, além de prover uma destinação adequada para os resíduos a usina traz retornos financeiros ao investidor dentro de um curto período de tempo, podendo, inclusive, servirem de recursos para as campanhas de conscientização ambiental dos seus consumidores.

Como limitações, o estudo não avaliou o potencial total de absorção dos produtos no mercado local, de tal forma que uma pesquisa de mercado é requerida 
caso haja o interesse de realizar o empreendimento aqui proposto, com o objetivo de mensurar a capacidade de absorção dos produtos fabricados e/ou verificar a possibilidade de empreender mais etapas ao coprocessamento para gerar produtos de maior valor agregado.

Além disso, a amostra utilizada para o estudo é referente aos clientes de uma única empresa. Desta forma, sugere-se em pesquisas futuras a utilização de amostras provenientes de um maior número de empresas, além da realização de comparativos a fim de avaliar se os resultados obtidos por este estudo se confirmam em outras regiões do Brasil. 


\section{REFERÊNCIAS}

ABREU, J. C. A. de; ARMOND-DEMELO, D. R.; LEOPOLDINO, C. B.. Entre fluxos e contra-fluxos: um estudo de caso sobre logística e sua aplicação na responsabilidade socioambiental. Revista Eletrônica de Ciência Administrativa, v. 10, n. I, p. 84-97. 20II. https://doi.org//0.5329/RECADM.20111001006

ALVES, V. da S.; VASCONCELOS, G.; MOREIRA, R. N.; ALVES FILHO, J. M.; BARRETO, S. Impacto Ambiental provocado pela destinação incorreta de Pneus. Revista Eniac, v. 4, n. 2, jul.-dez. p. 162-175. 2015.

ANIP. Institucional. Retrieved June 25, 2017, from http://www.anip. com.br/index.php?cont=institucional

BAUER, J. M.; CASSERES, M.; SAUERESSIG, G.; LUCHESE, J.; SELLITTO, M. A. . Destinação de pneus usados servíveis e inservíveis: dois estudos de caso. Revista Eletrônica em Gestão, Educação e Tecnologia Ambiental , v. 19, p. |292-I302, 2015.

BERTOLINI, G. R. F. . Modelo para Identificação do Volume de Investimento na Fabricação de Produtos Ecologicamente Corretos. Tese de Doutorado em Engenharia de Produção. Universidade Federal de Santa Catarina (UFSC). 2009

BRANDALISE, L.T.; BERTOLINI, G. R. F. Matriz de Classificação de Produtos Ecologicamente Corretos com Base na Análise do Ciclo de Vida do Produto. Revista Competitividade e Sustentabilidade, v. I, p. 0I-16.20I5.

BRANDALISE, L.T et al. Educação e gestão ambiental: sustentabilidade em ambientes competitivos. EBook Kindle, 2015.

BRAY, J.; JOHNS, N.; KILBURN, D..An exploratory study into the factors impeding ethical consumption. Journal of Business Ethics, v. 98, n. 4, p. 597-608. 20II.

CINTRA, C.; PAIVA, A.; BALDO, J.. Argamassas de revestimento para alvenaria contendo vermiculita expandida e agregados de borracha reciclada de pneus - Propriedades relevantes ( Masonry mortars containing expanded vermiculite and rubber aggregates. Cerâmica, v. 60, p. 69-76. 2014. https://doi.org//0.1590/S036669132014000100010

CONFEDERAÇÃO NACIONAL DA INDÚSTRIA. Proposta de implementação dos instrumentos econômicos previstos na lei $n^{\circ} 12.305 / 2010$ por meio de estímulos à cadeia de reciclagem e apoio aos setores produtivos obrigados à logística reversa. v. I4I, p. I-432. 2014. COOPER, R.. The design experience: The role of design and designers in the 21 century. Cornwall:Ashgate Publishing. 2002.

DONEY, P. M.; CANNON, J. P.. An examination of the nature of trust in buyer-seller relationships. Journal of Marketing, v. 6I, n.2, p. 35-5I. 1997.

FIORITI, C. F.; INO,A.;AKASAKI, J. L.. Análise experimental de blocos intertravados de concreto com adição de resíduos do processo de recauchutagem de pneus. Acta Scientiarum - Technology, v. 32, n. 3, p. 237-244. 2010. https://doi.org// 0.4025/actascitechnol.v32i3.60I3

FLORIANI, M. A.; FURLANETTO, V. C.; SEHNEM, S.. Descarte sustentável de pneus inservíveis. Navus: Revista de Gestão e Tecnologia, v. 6, p. 37-5I. 2016.

FREDERICO, E.; QUEVEDO-SILVA,
F.; DE LAMÔNICA FREIRE, O.

B.. Conquistando a confiança do consumidor: minimizando $\circ$ gap entre consciência ambiental e consumo ambiental. Revista de Gestão Ambiental e Sustentabilidade, v. 2, n. 2. 2013.

FREITAS, S. S.; NÓBREGA, C. C.. Os benefícios do coprocessamento de pneus inservíveis para a indústria cimenteira. Engenharia Sanitaria E Ambiental, v. 19, n. 3, p. 293-300. 2014. https://doi.org//0.1590/SI4I34|5220|4019000000769

GANESAN, S.. Determinants of long term orientation in buyer seller relationships. Journal of Marketing, v. 58, n. 2, p. I-19. 1994.

GARDIN, Josy A. C.; FIGUEIRÓ, P. S.; NASCIMENTO, L. F.. Logística Reversa De Pneus Inservíveis: Discussões Sobre Três Alternativas De Reciclagem Para Este Passivo Ambiental. Revista Gestão E Planejamento, v. II, n. 2, p. 232-249. 2010.

GITMAN, L. J. Princípios de administração financeira. Pearson. 2010.

GROHMANN, M. Z.; BATTISTELLA, L. F.;VELTER,A. N.; CASASOLA, F.. Comportamento Ecologicamente Consciente do Consumidor: Adaptação da Escala Eccb para o Contexto Brasileiro. Revista de Gestão Social e Ambiental, v. 6, n. I. 2012.

GUJEL, Â. A.; BRANDALISE, R. N.; GIOVANELA, M.; CRESPO, J. S.; NUNES, R. C. R.. Incorporação de pó de pneu em uma formulação para banda de rodagem de pneu de motocicleta. Polímeros, v. 18, n. 4, p. 320-325. 2008. https://doi.org// 0.1590/S0 I04|42820080004000 | |

GUO, S.; DAI, Q.; SI, R.; SUN; X.; LU, 
C.. Evaluation of properties and performance of rubber-modified concrete for recycling of waste scrap tire. Journal of Cleaner Production, v. 148 (February), p. 68I-689. 20I7.nhttps://doi.org/I0.10I6/j.jclepro.2017.02.046

HEAP, B.; KENT, J.. Towards sustainable consumption: an European perspective. London:The Royal Society. 2000.

JESUS, F.S.M.; BARBIERI, J. C..Atuação de Cooperativas de Catadores de Materiais Recicláveis na Logística Reversa Empresarial por meio de Comercialização Direta. Revista de Gestão Social e Ambiental, v.7, n. 3, p. 20. 2013.

KASHANI, A.; NGO, T. D.; MENDIS, P.; BLACK, J. R.; HAJIMOHAMMA$\mathrm{DI}, \mathrm{A}$.. A sustainable application of recycled tyre crumbs as insulator in lightweight cellular concrete. Journal of Cleaner Production, v. 149 (April), p. 925-935. 2017. https://doi.org/10.1016/j. jclepro.2017.02.154

KRAEMER, M. E. P.. Responsabilidade Ambiental Corporativa: Uma Contribuição das Empresas Para - Desenvolvimento Sustentável. Revista Eletrônica de Ciência Administrativa, v. 4, n. I. 2005.

KIM, C.; MAUBORGNE, R. A estratégia do oceano azul: como criar novos mercados e tornar a concorrência irrelevante. Rio de Janeiro: Campus-Elsevier, 2005

LAGARINHOS, C. A. F.; TENÓRIO, J.

A. S.. Logística reversa dos pneus usados no Brasil. Polímeros, v. 23 (ahead), p. 49-58. 20I2. https://doi.org/10.1590/S0104| 42820 | 2005000059

MEDDAH, A.; BEDDAR, M.; BALI, A. . Use of shredded rubber tire aggregates for roller compacted concrete pavement. Journal of Cleaner Production, v. 72 (June), p. 187-192. 2014. https://doi.or-
g/I0.10I6/j.jclepro.20I4.02.052

MELLONE, G.; SANTOS, M.R.; SHI-

BAO, F. Y.. Pavimentação de rodovias com a utilização de resíduos de pneus inservíveis. REGS, v.3 n.2, 2013. http://dx.doi. org/10.15603/2177-7284/regs. v3n0p489-508

MOORMAN, C.; DESHPANDE, R.; ZALTMAN, G.. Factors affecting trust in market research relationships. Journal of Marketing, v. 57, p. I, p. 8I- I0I. 1993.

MORGAN, R. M.; HUNT, S. D.. The commitment-trust theory of relationship marketing. Journal of Marketing, v. 58, n. 3, p. 20-38. 1994.

OLIVEIRA MARINHO, M. M.; AGRA FILHO, S. S.; ORRICO, S. R. M.; SANTOS, F. C.. Avaliação De Impacto Ambiental Como Instrumento De Estímulo À Produção Limpa: Desafios E Oportunidades No Estado Da Bahia. Revista de Gestão Social e Ambiental, v. 6, n.3, p. I29-14I. 2013.

ONUAGULUCHI, O.; PANESAR, D. K.. Hardened properties of concrete mixtures containing pre-coated crumb rubber and silica fume. Journal of Cleaner Production, v. 82(January), p. $|25-| 3 \mid$. 20|4. https://doi.org/I0.10I6/j.jclepro.20I4.06.068

RAMIREZ, G. G. D.; CASAGRANDE, M. D. T.; FOLLE, D.; PEREIRA, A.; PAULON, V.A.. Behavior of granular rubber waste tire reinforced soil for application in geosynthetic reinforced soil wall. Ibracon Structures and Materials Journal, v. 8, n. 4, p. 567-576. 2015. RODRIGUES, C. M.; HENKES, J. A.. Reciclagem De Pneus: Atitude Ambiental Aliada À Estratégia Eonômica. Revista Gestão Sustentabilidade Ambiental, v. 4, n. I, p. 448-473. 2015.

SADEK, D. M.; EL-ATTAR, M. M..
Structural behavior of rubberized masonry walls. Journal of Cleaner Production, v. 89 (July), p. 174-186. 2015. https://doi.org/10.1016/j.jclepro.2014.10.098

SELLITTO, M.A.; KADEL Jr., N.; BORCHARDT, M.; PEREIRA, G. M.; DOMINGUES, J.. Coprocessamento de cascas de arroz e pneus inservíveis e logística reversa na fabricação de cimento. Ambiente ; Sociedade, v. 16, n. I, p. $|4|-$ I62.20|3. https://doi.org//0.1590/ SI4|4-753X2013000100009

SILVA, J. P.; DAMO, J.. Plano De negócios para implantação de uma usina recicladora de pneus. Innovare, v.I, n. I. 2016.

SU, H.; YANG, J.; LING, T. C.; GHATAORA, G. S.; DIRAR, S.. Properties of concrete prepared with waste tyre rubber particles of uniform and varying sizes. Journal of Cleaner Production, v. 91, p. 288-296. 20I5. https://doi. org/I0.10I6/j.jclepro.20I4.12.022 THOMAS, B. S.; CHANDRA GUPTA, R.. Properties of high strength concrete containing scrap tire rubber. Journal of Cleaner Production, v. II 3 (February), p. 8692.2016. https://doi.org//0.1016/j. jclepro.2015.11.019

THOMAS, B. S.; GUPTA, R. C.; PANICKER, V. J.. Recycling of waste tire rubber as aggregate in concrete: Durability-related performance. Journal of Cleaner Production, v. 112 (February), p. 504-513. 2016. https://doi.org/l0.1016/j.jclepro.20I5.08.046

TORRETTA, V.; RADA, E. C.; RAGAZZI, M.;TRULLI, E.; ISTRATE, I. A.; CIOCA, L. I..Treatment and disposal of tyres:Two EU approaches.A review. Waste Management, v. 45 (May). 2015. https://doi.org/I0.10I6/j.wasman.2015.04.018 URUBURU, Á.; PONCE-CUETO, E.; COBO-BENITA, J. R.; ORDIERES- 
MERÉ, J.. The new challenges of VIEIRA, V. A.; FAIA, V. da S.. Efeitos end of life tyres management systems A Spanish case study. Waste Management, v. 33, n. 3, p. 679688. 2013. Retrieved from http://

www.sciencedirect.com/science/ ZANETTI, M. C.; FIORE, S.; RUarticle/pii/S0956053XI2004I87.
Moderadores Duplos e Triplos na Análise de Regressão. XXXVIII

Encontro Da Anpad, p. I-16. 2014. FFINO, B.; SANTAGATA, E.;
DALMAZZO, D.; LANOTTE, M.. Characterization of crumb rubber from end-of-life tyres for paving applications. Waste Management, v. 45 (July). 2015. https://doi.org/10.1016/j. wasman.20I5.05.003 